\title{
Analytical Assessment and Comparison of Wood Strength and Density Effect in the Design of Three Connection Types in Double-Shear
}

\author{
Elza M. M. Fonseca ${ }^{1,}{ }^{*}$, Pedro A. S. Leite ${ }^{1}$, Lino D. S. Silva ${ }^{1}$, Vânia S. B. Silva ${ }^{1}$ and Hernâni M. Lopes ${ }^{1}$ \\ 1 Mechanical Engineering Department, School of Engineering, Polytechnic Institute of Porto, Rua Dr. Bernar- \\ dino de Almeida, 431, 4200-072 Porto, Portugal; elz@isep.ipp.pt (E.M.M.F.); pedroasleite@sapo.pt (P.A.S.L.); \\ linodssil-va@gmail.com (L.D.S.S.); vania_sofiabs@hotmail.com (V.S.B.S.); hml@isep.ipp.pt (H.M.L.). \\ * Correspondence: elz@isep.ipp.pt
}

\begin{abstract}
This work presents the results of three connection types in double-shear with dowel fasteners, using the simplified equations from the Eurocode 5. All design parameters were established and compared using three different wood strength and density properties, which constitute the members connections. Eighty-one connections were obtained, allowing to conclude about the number of fasteners needed to the applied tensile load. An increase in the number of dowels was obtained with the increased applied tensile load, lower dowel diameter, lower wood density, and lower strength material in all connection types in the study. The design characteristic load-carrying capacity per shear plane and fastener also decrease with the previously considered parameters.
\end{abstract}

Keywords: load-carrying capacity; wood connection; dowel.

\section{Introduction}

Wood connections are the subject of studies by many researchers in various countries, they are considered one of the essential parts of a timber structure and therefore requires more considerable attention during the design. These connections are always the weakest parts of the structure. However, they govern the load-carrying capacity of the structure. Thus, the resistance and the durability of these types of structures are mainly dependent on the joints design between the elements [1]

The design of wood connections is highlighted more than timber members, such as beams and columns, to ensure the stability of the structure. Depending on which application, the connection has different options for the fasteners, using bolts or dowels, and steel plates, that are more prevalent on massive timber structures, since they can carry heavy loads [1]. There are three types of connections: the carpentry joints, the bonded connections, and the mechanical connections. The carpentry joints (traditional) are connected timber elements, usually subjected to compressive axial loads. These compression internal forces keep surfaces in close contact, often without any other devices, but with notches in the connected members. The carpenter connections are not included in Eurocode 5 and only national regulations are applied [2]. The bonded connections are usually employed to connect new members and reinforce existing members in timber structures. There are several types of bonded connections, such as structural finger joints and glued-in steel rods. This type of glued connection follows national regulations in design construction. This type of connections provides a higher fire rating as well as more aesthetically look in comparison with the dowel-type connections due to the inclusion of steel rods inside the timber member [3]. Mechanical connections are divided between dowel type fasteners and bearing type connections. Dowel type fasteners, such as bolts, screws, and nails, transmit either lateral or withdrawal loads. Lateral loads are transmitted by bearing stresses developed between the fastener and the members of the connection, and the withdrawal loads are axial loads parallel to the fastener axis transmitted through friction or bearing to 
the connected materials. Metal connector plates are a particular case of dowel type fasteners since they combine the lateral load actions of dowel fasteners and the strength properties of the metal plates $[2,4]$. Unlike the dowel fasteners, bearing type fasteners transmit lateral loads only. Bearing type fasteners, such as split-ring connectors and shear plates, transmit shear forces through bearing on the connected materials. Hanger-type connections are a combination of dowel and bearing-type fasteners where, generally, support one structural member and are connected to another member by a combination of dowel and bearing action $[2,4]$.

The selection of a fastener for a specific design application depends on the type of connection and the required strength capacity. Each connection must be designed to transmit forces effectively and provide acceptable performance for the life of the structure without causing cracking, or excessive deformation of the elements. The strength of mechanical fasteners is dependent on many factors, such as lumber species (density or specific gravity), angle of load to grain, the spacing of mechanical fasteners, and edge and end distances $[2,4]$.

The main objective of this work is to present the analytical formulation that can be applied in design of wood connections. Wood connections have been investigated due to their impact in construction engineering in terms of strength, ductility, and all capability to increase the structural performance in service [5-7]. In heavy timber structures, doubleshear wood connections with steel fasteners are widely used to assembly structural members and transfer loads [5]. The type connections in this study are wood-steel-wood (W-S$\mathrm{W})$, wood-to-wood (W-W-W) and steel-wood-steel (S-W-S) connections, both joined by steel dowels, in double shear, represented in Figure 1. The advantage of the presented study is the comparison between all these connections using the same design variables. It will be possible to identify the mechanical resistance and the needed dimensions versus the number of fasteners to be used in each one. The effect of wood strength and density was also investigated, and those variables are important to be considered in wood connections design.
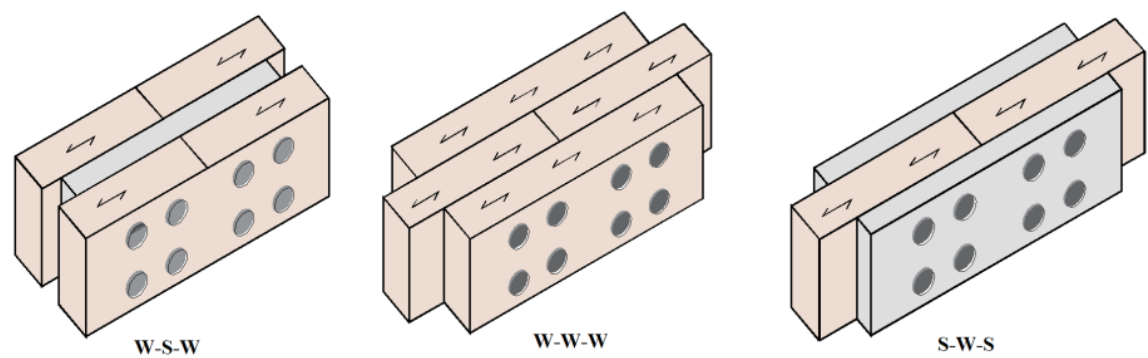

Figure 1. Wood connections in this study. Wood grain is parallel to the axial direction.

The analytical and design procedures follow simplified equations presented in Eurocode 5, part 1-1 [8]. To obtain the designed connections, this work is based on simplified and analytical equations to create a spreadsheet with several parameters. Different applied loads and steel dowel diameters were used, which allow to demonstrate the results for a safe design of wood connections in double shear at ambient temperature. Dowels are circular rods of timber, steel, or other materials as carbon-reinforced plastics. It is the generic term used for a fastener that transfers load between connected members by a combination of bending and shear in the dowel and shear and bearing (embedment) in the wood [9]. According to the procedure, the study could be used to improve the design. As a general conclusion, the calculated number of dowels increases with the applied tensile load. Lower dowel diameters have higher an effect on the needed number of fasteners. And it is still noticeable the increase of the needed number of dowels for lower wood strength and density.

\section{Wood Mechanical Properties: Glulam}


Wood consists of cellulose, hemicelluloses, lignin, and minor amounts (from $5 \%$ up to $10 \%$ ) of extraneous materials incorporated in the cellular structure. The cellular structure, which presents differences according to the volume and characteristics of these components make woods heavy or light, stiff or flexible, and hard or soft. The properties of a single species are relatively constant within its limits. Thus, the selection of wood by species will be suitable [10]. Wood may be described as an orthotropic material, it has unique and independent mechanical properties in the directions of three mutually perpendicular axes: longitudinal, radial, and tangential.

In this work, three different wood species in homogeneous glued laminated (glulam) were considered for the designed connections, where the density properties vary between 370 and $480 \mathrm{~kg} / \mathrm{m}^{3}$. The three types of glued laminated wood are GL20H, GL24H, and GL32H, which are commonly applied in construction engineering. CEN BS EN1194, 1999 [10] lists eight glulam strength classes. To distinguish them from the wood categories, they are designated by GLxH as homogeneous lay-up, meaning that all the laminations are of the same grade (strength class) and species (or species combinations), or GLxC as combined, where the cross section comprises inner and outer laminations of different grades (strength classes) and species (or species combinations) [12]. The designation GL refers to the fact that it is a laminated glued wood; the number $(x)$ which appears in the designation defines its resistance to bending. The mechanical properties for the chosen glulam wood used in this study are presented in Table 1 [10-11, 13].

Table 1. Mean values of mechanical properties for homogeneous glulam at approximately $12 \%$ moisture content [10-11, 13].

\begin{tabular}{cccc}
\hline Mechanical Properties & GL20H & GL24H & GL32H \\
\hline Average parallel-to-grain tensile strength, $f_{t, 0, k}, \mathrm{~N} / \mathrm{mm}^{2}$ & 16 & 19.2 & 25.6 \\
\hline Young's Modulus, $E, \mathrm{~N} / \mathrm{mm}^{2}$ & 8400 & 11500 & 14200 \\
\hline Density, $\rho_{k}, \mathrm{~kg} / \mathrm{m}^{3}$ & 370 & 420 & 480 \\
\hline
\end{tabular}

\section{Simplified Equations in Designed Wood Connections}

Theoretical models have been developed to determine the characteristic values of the connection load-carrying capacity by a calculation based on the certain material properties and dimensions of the connection [14]. Eurocode 5 part 1-1 [8] provides simplified equations for calculating the load-carrying capacity of single-shear plane and doubleshear plane in different connection types. In double-shear plane connections, the resistance of each shear plane should be determined by assuming which each one of them is part of three-member connections. The basic prerequisite for the calculation is the symmetrical arrangement of the connection [14]. To the design of wood connections under double shear, the aim is to determine the main dimensions (width, height, thickness of the wood elements and steel plate, minimum spacing and edge/end distances between the dowels and the wood plate). The number of dowels is an important parameter in the connection design with the arrangement by lines and columns. The connections are verified to satisfy double shear by considering several potential failure modes. These will depend on the penetration lengthy of the dowel in the elements, the strength of the localized crushing, the dowel diameter, and the characteristic yield moment of the fastener.

During this study, different parameters are considered for the three studied connections: tensile applied load $F_{d}$, dowel diameter $d$, the wooden board thickness $t_{1}$ (smaller thickness of the wood side member or the penetration depth), $t_{2}$ (thickness of the wood middle member) and the steel plate thickness $t_{s}$. To calculate the dimension of each connection type, the load was considered as parallel to the grain direction, [15-16]. The present study compares the performance of the three different types of connections as a function of the different variables, and based on the works previously started [7, 17-18].

The following equations are considered for connection in double-shear, where the dowel diameter should be greater than $6 \mathrm{~mm}$ and small than $30 \mathrm{~mm}$. According to the 
Eurocode 5, part 1-1 [8], the design tensile strength along the grain $f_{t, 0, d}$, must be equal or higher than the design tensile stress along the grain $\sigma_{t, 0, d}$. The tensile strength $f_{t, 0, d}$, defined by Equation (1), represents a reduced value of its characteristic value along the wood grain $f_{t, 0, k}$, due to the application of two safety factors: the modification factor for load duration and moisture content $k_{\bmod }$, equal to 0,8 , and the partial factor for material property $\gamma_{M}$ equal to 1.25 , according to Eurocode 5 part 1-1 [8].

$$
f_{t, 0, d}=\frac{f_{t, 0, k} k_{m o d}}{\gamma_{M}}
$$

Considering $A_{s}$ the cross-section of the member, the design tensile stress along the grain $\sigma_{t, 0, d}$ is calculated using Equation (2), Eurocode 5, part 1-1 [8].

$$
\sigma_{t, 0, d}=\frac{F_{d}}{A_{s}}
$$

For symmetrical connections in double shear, the characteristic load-carrying capacity per shear plane and fastener $F_{v, R k}$, is obtained according to the Eurocode 5 part 1-1 [8]. These equations are based on a theory developed by Johansen $[9,14]$. The associated connection strength equations derived by Johansen [9] are dependent on the geometry of the connection, the embedment strength of the wood and the bending strength of the fastener. In the deriving of these equations, however, the friction forces between the connected members were ignored as well as the withdrawal resistance of the fasteners. To include these effects, the characteristic load-carrying capacity of a fastener is given by the Equations (3) to (6) [9, 14], according to the Eurocode 5 part 1-1 [8]. For symmetrical connections in double shear, the characteristic load-carrying capacity per shear plane and fastener will be the minimum value of these three equations, and the failure mode will be the mode associated with each equation, Figures 2 to 4 .

Using all proposed simplified equations from Eurocode 5, part 1-1 [8], the characteristic load-carrying capacity per shear plane and fastener $F_{v, R k}$, for the case of the wood connection has an internal steel plate of any thickness (W-S-W) are given by the Equations in (3).

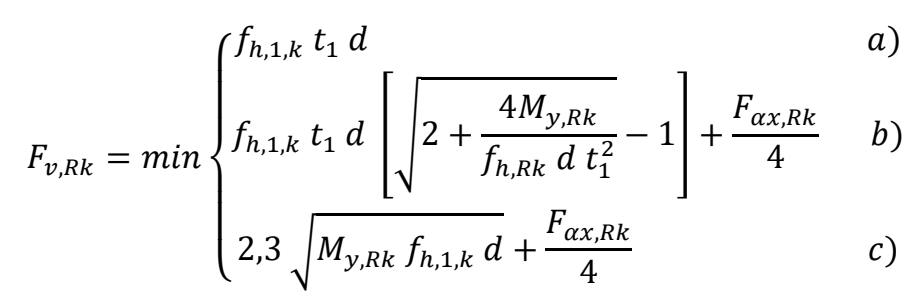

For the double shear connection with a steel plate of any thickness as the central member, the different failure modes are represented in Figure 2, relative to the characteristic load-carrying capacity per shear plane and fastener calculated in Equation (3). In Figure 2 the failure mode in $3 a$ represents embedment of the wood, the failure mode in $3 b$ represents bending of the fastener and the failure mode $3 \mathrm{c}$ is the combination of the previous mentioned modes.

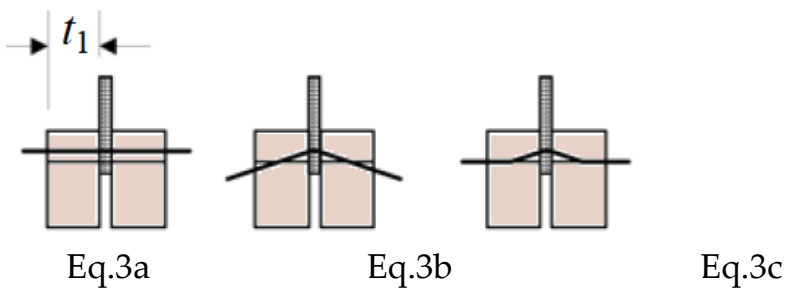

Figure 2. Failure modes for wood-steel-wood connections in double shear [8].

For a wood-to-wood connection (W-W-W) with dowels, the characteristic load-carrying capacity are given by the Equations in (4). 


$$
F_{v, R k}=\min \begin{cases}f_{h, 1, k} t_{1} d & a) \\ 0,5 f_{h, 2, k} t_{2} d & b) \\ 1,05 \frac{f_{h, 1, k} t_{1} d}{2+\beta}\left[\sqrt{\left.2 \beta(1+\beta)+\frac{4 \beta(2+\beta) M_{y, R k}}{f_{h, R k} d t_{1}^{2}}-\beta\right]+\frac{F_{\alpha x, R k}}{4}}\right. & c) \\ 1,15 \sqrt{\frac{2 \beta}{1+\beta} \sqrt{2 M_{y, R k} f_{h, 1, k} d}+\frac{F_{\alpha x, R k}}{4}} & d)\end{cases}
$$

The four modes of failure for wood-to-wood connections are illustrated in Figure 3, which corresponds, respectively, to the four characteristic load-carrying capacities given by the Equations $4 \mathrm{a}, 4 \mathrm{~b}, 4 \mathrm{c}$ and $4 \mathrm{~d}$.

The mode of failure 4a represents the bearing failure of the edge members, mode of failure $4 \mathrm{~b}$ represents the bearing failure of the central member, mode of failure $4 \mathrm{c}$ represents simultaneous plastic hinge formation in the fastener inside the central member and bearing failure of all members and mode of failure $\mathrm{d} 4$ represents the simultaneous plastic hinge formation in the fastener inside all members and bearing failure of all members.

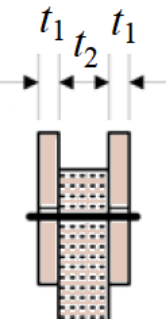

Eq.4a

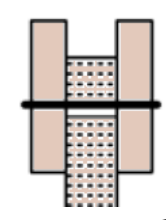

Eq. $4 \mathrm{~b}$

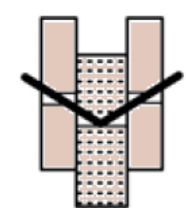

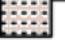

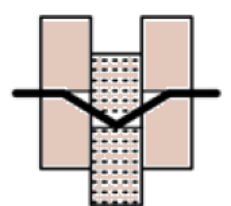

Eq.4c
Eq.4d

Figure 3. Failure modes for wood-wood-wood connections in double shear [8].

For a steel-to-wood connection (S-W-S) the characteristic load-carrying capacity depends on the thickness of the steel plates, Eurocode 5 part 1-1 [8], which are given by the Equations in (5) and in (6). The thickness of steel plates less than or equal to 0.5 multiplied by dowel diameter are classified as thin plates, and greater than or equal to the diameter are classified as thick plates [8]. The characteristic load-carrying capacity of connections with steel plate thickness between a thin and a thick plate should be calculated by linear interpolation between the previous values [8].

For a double shear connection, the characteristic load-carrying capacity using thick steel plates as the outer members are given by the Equations in (5):

$$
F_{v, R k}=\min \begin{cases}0,5 f_{h, 2, k} t_{2} d & a) \\ 2,3 \sqrt{2 M_{y, R k} f_{h, 2, k} d}+\frac{F_{a x, R k}}{4} & \text { b) }\end{cases}
$$

In the studied connections, the external steel plate has a thickness equal to $3 \mathrm{~mm}$, which is classified as a thin plate. For this condition, when steel plates are the outer members of a double shear connection, the characteristic load-carrying capacity is obtained using the Equations in (6).

$$
F_{v, R k}=\min \begin{cases}0,5 f_{h, 2, k} t_{2} d & a) \\ 1,15 \sqrt{2 M_{y, R k} f_{h, 2, k} d}+\frac{F_{a x, R k}}{4} & b)\end{cases}
$$

where: $f_{h, i, k}\left(f_{h, 1, k}\right.$ or $\left.f_{h, 2, k}\right)$ is the characteristic embedment strength in timber member $i ; M_{y, R k}$ is the characteristic yield moment of the fastener, $\beta$ is the ratio between the embedment strength of the members considered equal to 1 , and $F_{\alpha x, R k}$ represents the characteristic axial withdrawal capacity of the fastener, according to the Eurocode 5 part 1-1 [8]. The three different modes of failures are shown in Figure 4, beeing the characteristic load-carrying capacity obtained from Equations (5) and (6). The failure mode in 5a/6a 
represents the wood embedment, the failure mode in $5 \mathrm{~b}$ the bending of the fastener, and failure mode $6 \mathrm{~b}$ is the combination of the previous failure modes.

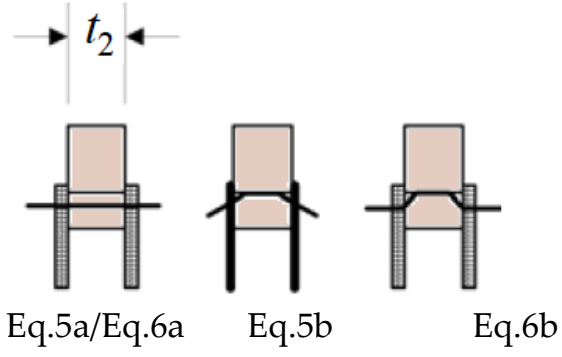

Figure 4. Failure modes for steel-wood-steel connections in double shear [8].

The value of the characteristic embedment strength in timber member $i$ parallel to the grain with pre-drilled holes is obtained due to the value of the dowel diameter between $6 \mathrm{~mm}$ and $30 \mathrm{~mm}$, and the characteristic wood density $\rho_{k}$, as defined in Equation (7).

$$
f_{h, 1, k}=f_{h, 2, k}=0,082(1-0,01 d) \rho_{k}
$$

The value of $M_{y, R k}$ is calculated according to the dowel diameter d, and its material characteristic tensile strength $f_{u, k}$.

$$
M_{y, R k}=0,3 f_{u, k} d^{2,6}
$$

After calculated the value of $F_{v, R k}$, it is necessary to determine the design value of the characteristic load-carrying capacity per shear plane and fastener, being this obtained from Equation (9), in which is considered two safety factors, defined according to the Eurocode 5 part 1-1 [8]. The partial factor for material property $\gamma_{M}$ is equal to 1.25 for glued laminated timber. The modification factor considering the effect of the duration of load and moisture content $k_{\text {mod }}$ is equal to 0.8 , for load-duration class in medium term action and for glued laminated timer.

$$
F_{v, R d}=\frac{F_{v, R k} k_{m o d}}{\gamma_{M}}
$$

Finally, with the calculation from $F_{v, R d}$, it is possible to obtain the number of the bolts, being this given by the Equation (10).

$$
N \geq \frac{F_{d}}{F_{v, R d}}
$$

To reduce the risk of failure modes, the minimum edge, and spacing criteria for connections with dowel were calculated [7]. The arrangement between dowels is according to the calculated spacing, following the Equations (11) to (14): parallel to the grain of fastener and within one row $a_{1}$, perpendicular to the grain and between rows $a_{2}$, the distance between fasteners and loaded end $a_{3, t}$ and unloaded edge $a_{4}, c$, which varies according to the dowel diameter. The parameter $\alpha$ represents the angle, between the applied tensile load and the wood grain direction.

$$
\begin{gathered}
a_{1}=(3+2|\cos \cos \alpha|) d \\
a_{2}=3 d \\
a_{3, t}=\max (7 d ; 80 \mathrm{~mm}) \\
a_{4, c}=3 d
\end{gathered}
$$


According to the Eurocode 5 part 1-1 [4], the dowels arrangements are given by Figure 5 .
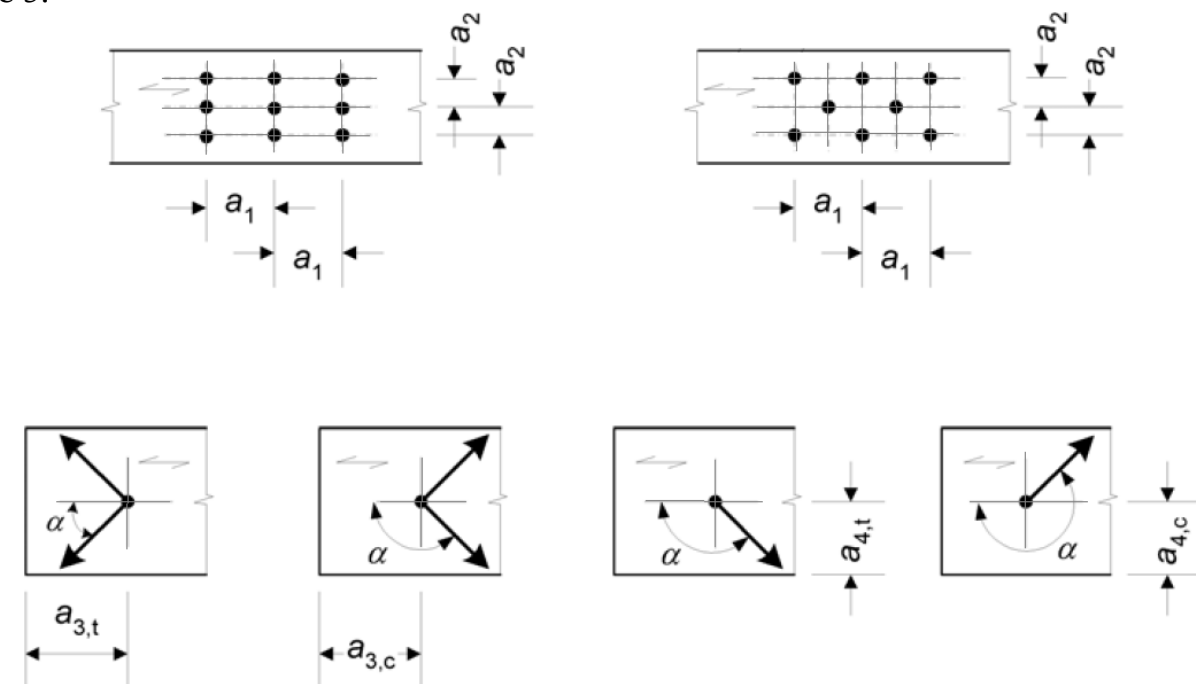

$-90^{\circ} \leq \alpha \leq 90^{\circ}$

$90^{\circ} \leq \alpha \leq 270^{\circ}$

$0^{\circ} \leq \alpha \leq 180^{\circ}$

$180^{\circ} \leq \alpha \leq 360^{\circ}$

Figure 5. Dowels arrangements according to the Eurocode 5 part 1-1 [4].

\section{Designed Connections in Accordance with Eurocode 5 part 1-1}

A spreadsheet with all parameters was developed to verify the load-carrying capacity of the connection, the cross-section, the number of fasteners, and the minimum spacing in edges, according to the Eurocode 5, part 1-1 [8]. For this study, three dowel diameters $(6,8$ and $10 \mathrm{~mm})$, three applied tensile loads $(10,15$ and $20 \mathrm{kN})$, and three wood materials (GL20H, GL24H and GL32H) were considered. The number of calculated dowels were distributed in lines and columns, being considered 3 the fixed number of columns. Also, the wooden board thickness $t_{1}$ and $t_{2}$ were chosen equal to $45 \mathrm{~mm}$. For unprotected connections with side members of wood, the thickness of the members should be greater than $45 \mathrm{~mm}$, according to Eurocode 5 part 1-2 [19]. The thickness of the steel plate inside the connection was equal to $6 \mathrm{~mm}$ and external to connection equal to $3 \mathrm{~mm}$. A total of 81 connections were studied, 27 per connection type.

Tables 2, 3 and 4 show all design parameters needed for all different connection types, namely: dowel diameter and length, dowel arrangement and distances, connection member dimensions and the design characteristic load-carrying per shear plane and fastener. These allow to establish the relationship between the wood strength and density, the dowel diameter, and the applied tensile load, to determine the needed number of dowels.

Figures 6, 7 and 8 represent a linear correlation between all design parameters for three types of connections in the study. This show that the number of dowels increased to small diameters and lower wood strength and density. Using the same design parameters, the S-W-S connections need a higher number of dowels when compared with the other types of studied connections. In general, when using higher dowel diameters, the wood density effect is not relevant. The wood strength and density carry out a relative influence when the connections have small dowel diameters. 
Table 2. Design parameters for W-S-W connections.

\begin{tabular}{|c|c|c|c|c|c|c|c|c|c|c|c|c|c|c|}
\hline Load, $F_{d}$ & \multicolumn{2}{|c|}{ Dowel } & \multirow{2}{*}{\multicolumn{2}{|c|}{ Dowel arrangement }} & \multicolumn{4}{|c|}{ Distances } & \multicolumn{4}{|c|}{ Connection dimensions } & \multirow{2}{*}{$\begin{array}{c}\begin{array}{c}\text { Design tensile } \\
\text { stress }\end{array} \\
{\left[\mathrm{N} / \mathrm{mm}^{2}\right]}\end{array}$} & \multirow{2}{*}{\begin{tabular}{|c}
$\begin{array}{c}\text { Design characteristic } \\
\text { load-carrying }\end{array}$ \\
{$[\mathrm{N}]$}
\end{tabular}} \\
\hline$[\mathrm{kN}]$ & \multicolumn{2}{|c|}{$[\mathrm{mm}]$} & & & \multicolumn{4}{|c|}{$[\mathrm{mm}]$} & \multicolumn{4}{|c|}{$[\mathrm{mm}]$} & & \\
\hline & $d$ & length & $\mathrm{N}$ Lines & N Columns & $a_{1}$ & $a_{2}$ & $a_{3, t}$ & $a_{4, c}$ & $t_{1}$ & $t_{s}$ & $\mathrm{H}$ & $L$ & $\sigma_{t, 0, d}$ & $F_{v, R d}$ \\
\hline \multicolumn{15}{|c|}{$\mathrm{GL2OH}$} \\
\hline \multirow{3}{*}{10} & 6 & 96 & 2 & 3 & 30 & 18 & 80 & 18 & 45 & 6 & 54 & 440 & 10,24 & 2166,4 \\
\hline & 8 & 96 & 2 & 3 & 40 & 24 & 80 & 24 & 45 & 6 & 72 & 480 & 10,24 & 3186,7 \\
\hline & 10 & 96 & 2 & 3 & 50 & 30 & 80 & 30 & 45 & 6 & 90 & 520 & 10,24 & 4180,0 \\
\hline \multirow{3}{*}{15} & 6 & 96 & 3 & 3 & 30 & 18 & 80 & 18 & 45 & 6 & 72 & 440 & 10,24 & 2166,4 \\
\hline & 8 & 96 & 2 & 3 & 40 & 24 & 80 & 24 & 45 & 6 & 72 & 482 & 10,24 & 3186,7 \\
\hline & 10 & 96 & 2 & 3 & 50 & 30 & 80 & 30 & 45 & 6 & 90 & 520 & 10,24 & 4180,0 \\
\hline \multirow{3}{*}{20} & 6 & 96 & 4 & 3 & 30 & 18 & 80 & 18 & 45 & 6 & 90 & 400 & 10,24 & 2166,4 \\
\hline & 8 & 96 & 3 & 3 & 40 & 24 & 80 & 24 & 45 & 6 & 96 & 480 & 10,24 & 3186,7 \\
\hline & 10 & 96 & 2 & 3 & 50 & 30 & 80 & 30 & 45 & 6 & 90 & 520 & 10,24 & 4180,0 \\
\hline \multicolumn{15}{|c|}{ GL24H } \\
\hline \multirow{3}{*}{10} & 6 & 96 & 2 & 3 & 30 & 18 & 80 & 18 & 45 & 6 & 54 & 440 & 12,29 & 2308,1 \\
\hline & 8 & 96 & 2 & 3 & 40 & 24 & 80 & 24 & 45 & 6 & 72 & 480 & 12,29 & 3548,4 \\
\hline & 10 & 96 & 2 & 3 & 50 & 30 & 80 & 30 & 45 & 6 & 90 & 520 & 12,29 & 4624,5 \\
\hline \multirow{3}{*}{15} & 6 & 96 & 3 & 3 & 30 & 18 & 80 & 18 & 45 & 6 & 72 & 440 & 12,29 & 2308,2 \\
\hline & 8 & 96 & 2 & 3 & 40 & 24 & 80 & 24 & 45 & 6 & 72 & 482 & 12,29 & 3548,4 \\
\hline & 10 & 96 & 2 & 3 & 50 & 30 & 80 & 30 & 45 & 6 & 90 & 520 & 12,29 & 4624,5 \\
\hline \multirow{3}{*}{20} & 6 & 96 & 3 & 3 & 30 & 18 & 80 & 18 & 45 & 6 & 90 & 400 & 12,29 & 2308,2 \\
\hline & 8 & 96 & 2 & 3 & 40 & 24 & 80 & 24 & 45 & 6 & 72 & 480 & 12,29 & 3548,4 \\
\hline & 10 & 96 & 2 & 3 & 50 & 30 & 80 & 30 & 45 & 6 & 90 & 520 & 12,29 & 4624,5 \\
\hline \multicolumn{15}{|c|}{ GL32H } \\
\hline \multirow{3}{*}{10} & 6 & 96 & 2 & 3 & 30 & 18 & 80 & 18 & 45 & 6 & 54 & 440 & 16,38 & 2467,5 \\
\hline & 8 & 96 & 1 & 3 & 40 & 24 & 80 & 24 & 45 & 6 & 48 & 480 & 16,38 & 3982,0 \\
\hline & 10 & 96 & 1 & 3 & 50 & 30 & 80 & 30 & 45 & 6 & 60 & 520 & 16,38 & 5156,7 \\
\hline \multirow{3}{*}{15} & 6 & 96 & 3 & 3 & 30 & 18 & 80 & 18 & 45 & 6 & 72 & 440 & 16,38 & 2467,5 \\
\hline & 8 & 96 & 2 & 3 & 40 & 24 & 80 & 24 & 45 & 6 & 72 & 482 & 16,38 & 3982,0 \\
\hline & 10 & 96 & 1 & 3 & 50 & 30 & 80 & 30 & 45 & 6 & 60 & 520 & 16,38 & 5156,7 \\
\hline \multirow{3}{*}{20} & 6 & 96 & 3 & 3 & 30 & 18 & 80 & 18 & 45 & 6 & 54 & 400 & 16,38 & 2467,5 \\
\hline & 8 & 96 & 2 & 3 & 40 & 24 & 80 & 24 & 45 & 6 & 72 & 480 & 16,38 & 3982,0 \\
\hline & 10 & 96 & 2 & 3 & 50 & 30 & 80 & 30 & 45 & 6 & 90 & 520 & 16,38 & 5156,7 \\
\hline
\end{tabular}

Table 3. Design parameters for $\mathrm{W}-\mathrm{W}-\mathrm{W}$ connections.

\begin{tabular}{|c|c|c|c|c|c|c|c|c|c|c|c|c|c|c|}
\hline Load, $F_{d}$ & \multirow{2}{*}{\multicolumn{2}{|c|}{$\begin{array}{l}\text { Dowel } \\
{[\mathrm{mm}]} \\
\end{array}$}} & \multirow{2}{*}{\multicolumn{2}{|c|}{ Dowel arrangement }} & \multicolumn{4}{|c|}{ Distances } & \multicolumn{4}{|c|}{ Connection dimensions } & \multirow{3}{*}{$\begin{array}{c}\begin{array}{c}\text { Design tensile } \\
\text { stress }\end{array} \\
{\left[\mathrm{N} / \mathrm{mm}^{2}\right]} \\
\sigma_{t, o, d} \\
\end{array}$} & \multirow{3}{*}{$\begin{array}{c}\text { Design characteristic } \\
\text { load-carrying } \\
{[\mathrm{N}]} \\
\boldsymbol{F}_{\mathrm{v}, \mathrm{Rd}} \\
\end{array}$} \\
\hline \multirow[t]{2}{*}[\mathrm{kN}]{} & & & & & \multicolumn{4}{|c|}{ [mm] } & \multicolumn{4}{|c|}{ [mm] } & & \\
\hline & $d$ & length & $\mathrm{N}$ Lines & N Columns & $a_{1}$ & $a_{2}$ & $a_{3, t}$ & $a_{4, c}$ & $t_{1}$ & $t_{2}$ & $H$ & $L$ & & \\
\hline \multicolumn{15}{|c|}{ GL2OH } \\
\hline \multirow{3}{*}{10} & 6 & 135 & 3 & 3 & 30 & 18 & 80 & 18 & 45 & 45 & 72 & 440 & 10,24 & 1531,9 \\
\hline & 8 & 135 & 2 & 3 & 40 & 24 & 80 & 24 & 45 & 45 & 72 & 480 & 10,24 & 2543,6 \\
\hline & 10 & 135 & 1 & 3 & 50 & 30 & 80 & 30 & 45 & 45 & 60 & 520 & 10,24 & 3424,8 \\
\hline \multirow{3}{*}{15} & 6 & 135 & 4 & 3 & 30 & 18 & 80 & 18 & 45 & 45 & 90 & 440 & 10,24 & 1531,9 \\
\hline & 8 & 135 & 2 & 3 & 40 & 24 & 80 & 24 & 45 & 45 & 72 & 480 & 10,24 & 2543,6 \\
\hline & 10 & 135 & 2 & 3 & 50 & 30 & 80 & 30 & 45 & 45 & 90 & 520 & 10,24 & 3424,8 \\
\hline \multirow{3}{*}{20} & 6 & 135 & 5 & 3 & 30 & 18 & 80 & 18 & 45 & 45 & 108 & 440 & 10,24 & 1531,9 \\
\hline & 8 & 135 & 3 & 3 & 40 & 24 & 80 & 24 & 45 & 45 & 96 & 480 & 10,24 & 2543,6 \\
\hline & 10 & 135 & 2 & 3 & 50 & 30 & 80 & 30 & 45 & 45 & 90 & 520 & 10,24 & 3424,8 \\
\hline \multicolumn{15}{|c|}{ GL24H } \\
\hline \multirow{3}{*}{10} & 6 & 135 & 3 & 3 & 30 & 18 & 80 & 18 & 45 & 45 & 72 & 440 & 12,29 & 1632,1 \\
\hline & 8 & 135 & 2 & 3 & 40 & 24 & 80 & 24 & 45 & 45 & 72 & 480 & 12,29 & 2710 \\
\hline & 10 & 135 & 1 & 3 & 50 & 30 & 80 & 30 & 45 & 45 & 60 & 520 & 12,29 & 3801,2 \\
\hline \multirow{3}{*}{15} & 6 & 135 & 4 & 3 & 30 & 18 & 80 & 18 & 45 & 45 & 90 & 440 & 12,29 & 1632,1 \\
\hline & 8 & 135 & 2 & 3 & 40 & 24 & 80 & 24 & 45 & 45 & 72 & 480 & 12,29 & 2710 \\
\hline & 10 & 135 & 2 & 3 & 50 & 30 & 80 & 30 & 45 & 45 & 90 & 520 & 12,29 & 3801,2 \\
\hline \multirow{3}{*}{20} & 6 & 135 & 5 & 3 & 30 & 18 & 80 & 18 & 45 & 45 & 108 & 440 & 12,29 & 1632,1 \\
\hline & 8 & 135 & 3 & 3 & 40 & 24 & 80 & 24 & 45 & 45 & 96 & 480 & 12,29 & 2710 \\
\hline & 10 & 135 & 2 & 3 & 50 & 30 & 80 & 30 & 45 & 45 & 90 & 520 & 12,29 & 3801,2 \\
\hline \multicolumn{15}{|c|}{ GL32H } \\
\hline \multirow{3}{*}{10} & 6 & 135 & 2 & 3 & 30 & 18 & 80 & 18 & 45 & 45 & 72 & 440 & 16,38 & 1744,8 \\
\hline & 8 & 135 & 2 & 3 & 40 & 24 & 80 & 24 & 45 & 45 & 72 & 480 & 16,38 & 2897,1 \\
\hline & 10 & 135 & 1 & 3 & 50 & 30 & 80 & 30 & 45 & 45 & 60 & 520 & 16,38 & 4251,2 \\
\hline \multirow{3}{*}{15} & 6 & 135 & 3 & 3 & 30 & 18 & 80 & 18 & 45 & 45 & 90 & 440 & 16,38 & 1744,8 \\
\hline & 8 & 135 & 2 & 3 & 40 & 24 & 80 & 24 & 45 & 45 & 72 & 480 & 16,38 & 2897,1 \\
\hline & 10 & 135 & 2 & 3 & 50 & 30 & 80 & 30 & 45 & 45 & 90 & 520 & 16,38 & 4251,2 \\
\hline \multirow{3}{*}{20} & 6 & 135 & 4 & 3 & 30 & 18 & 80 & 18 & 45 & 45 & 108 & 440 & 16,38 & 1744,8 \\
\hline & 8 & 135 & 3 & 3 & 40 & 24 & 80 & 24 & 45 & 45 & 96 & 480 & 16,38 & 2897,1 \\
\hline & 10 & 135 & 2 & 3 & 50 & 30 & 80 & 30 & 45 & 45 & 90 & 520 & 16,38 & 4251,2 \\
\hline
\end{tabular}


Table 4. Design parameters for S-W-S connections.

\begin{tabular}{|c|c|c|c|c|c|c|c|c|c|c|c|c|c|c|}
\hline Load, $\boldsymbol{F}_{d}$ & \multicolumn{2}{|c|}{ Dowel } & \multicolumn{2}{|c|}{ Dowel arrangement } & \multicolumn{4}{|c|}{ Distances } & \multicolumn{4}{|c|}{ Connection dimensions } & \multirow{2}{*}{$\begin{array}{c}\begin{array}{c}\text { Design tensile } \\
\text { stress }\end{array} \\
{\left[\mathrm{N} / \mathrm{mm}^{2}\right]} \\
\end{array}$} & \multirow{2}{*}{\begin{tabular}{|c}
$\begin{array}{c}\text { Design characteristic } \\
\text { load-carrying }\end{array}$ \\
{$[\mathrm{N}]$} \\
\end{tabular}} \\
\hline$[\mathrm{kN}]$ & \multicolumn{2}{|c|}{ [mm] } & & & \multicolumn{4}{|c|}{ [mm] } & \multicolumn{4}{|c|}{ [mm] } & & \\
\hline & $d$ & length & $\mathrm{N}$ Lines & N Columns & $a 1$ & $a 2$ & $a 3, t$ & $a 4, c$ & $t 1$ & ts & $H$ & $L$ & $\sigma_{t, o, d}$ & $\boldsymbol{F}_{\mathrm{V}, R d}$ \\
\hline \multicolumn{15}{|c|}{$\mathrm{GL} 2 \mathrm{OH}$} \\
\hline \multirow{3}{*}{10} & 6 & 51 & 3 & 3 & 30 & 18 & 80 & 18 & 45 & 3 & 72 & 440 & 10,24 & 1393,1 \\
\hline & 8 & 51 & 2 & 3 & 40 & 24 & 80 & 24 & 45 & 3 & 72 & 480 & 10,24 & 2313,2 \\
\hline & 10 & 51 & 1 & 3 & 50 & 30 & 80 & 30 & 45 & 3 & 60 & 520 & 10,24 & 3418,8 \\
\hline \multirow{3}{*}{15} & 6 & 51 & 4 & 3 & 30 & 18 & 80 & 18 & 45 & 3 & 90 & 440 & 10,24 & 1393,1 \\
\hline & 8 & 51 & 3 & 3 & 40 & 24 & 80 & 24 & 45 & 3 & 96 & 480 & 10,24 & 2313,2 \\
\hline & 10 & 51 & 2 & 3 & 50 & 30 & 80 & 30 & 45 & 3 & 90 & 520 & 10,24 & 3418,8 \\
\hline \multirow{3}{*}{20} & 6 & 51 & 5 & 3 & 30 & 18 & 80 & 18 & 45 & 3 & 108 & 440 & 10,24 & 1393,1 \\
\hline & 8 & 51 & 3 & 3 & 40 & 24 & 80 & 24 & 45 & 3 & 96 & 480 & 10,24 & 2313,2 \\
\hline & 10 & 51 & 2 & 3 & 50 & 30 & 80 & 30 & 45 & 3 & 90 & 520 & 10,24 & 3418,8 \\
\hline \multicolumn{15}{|c|}{ GL24H } \\
\hline \multirow{3}{*}{10} & 6 & 51 & 3 & 3 & 30 & 18 & 80 & 18 & 45 & 3 & 72 & 440 & 12,29 & 1482,4 \\
\hline & 8 & 51 & 2 & 3 & 40 & 24 & 80 & 24 & 45 & 3 & 72 & 480 & 12,29 & 2461,5 \\
\hline & 10 & 51 & 1 & 3 & 50 & 30 & 80 & 30 & 45 & 3 & 60 & 520 & 12,29 & 3638 \\
\hline \multirow{3}{*}{15} & 6 & 51 & 4 & 3 & 30 & 18 & 80 & 18 & 45 & 3 & 90 & 440 & 12,29 & 1482,4 \\
\hline & 8 & 51 & 3 & 3 & 40 & 24 & 80 & 24 & 45 & 3 & 96 & 480 & 12,29 & 2461,5 \\
\hline & 10 & 51 & 2 & 3 & 50 & 30 & 80 & 30 & 45 & 3 & 90 & 520 & 12,29 & 3638 \\
\hline \multirow{3}{*}{20} & 6 & 51 & 5 & 3 & 30 & 18 & 80 & 18 & 45 & 3 & 108 & 440 & 12,29 & 1482,4 \\
\hline & 8 & 51 & 3 & 3 & 40 & 24 & 80 & 24 & 45 & 3 & 96 & 480 & 12,29 & 2461,5 \\
\hline & 10 & 51 & 2 & 3 & 50 & 30 & 80 & 30 & 45 & 3 & 90 & 520 & 12,29 & 3638 \\
\hline \multicolumn{15}{|c|}{ GL32H } \\
\hline \multirow{3}{*}{10} & 6 & 51 & 3 & 3 & 30 & 18 & 80 & 18 & 45 & 3 & 72 & 440 & 16,38 & 1584,8 \\
\hline & 8 & 51 & 2 & 3 & 40 & 24 & 80 & 24 & 45 & 3 & 72 & 480 & 16,38 & 2631,4 \\
\hline & 10 & 51 & 1 & 3 & 50 & 30 & 80 & 30 & 45 & 3 & 60 & 520 & 16,38 & 3889,2 \\
\hline \multirow{3}{*}{15} & 6 & 51 & 4 & 3 & 30 & 18 & 80 & 18 & 45 & 3 & 90 & 440 & 16,38 & 1584,8 \\
\hline & 8 & 51 & 3 & 3 & 40 & 24 & 80 & 24 & 45 & 3 & 96 & 480 & 16,38 & 2631,4 \\
\hline & 10 & 51 & 2 & 3 & 50 & 30 & 80 & 30 & 45 & 3 & 90 & 520 & 16,38 & 3889,2 \\
\hline \multirow{3}{*}{20} & 6 & 51 & 5 & 3 & 30 & 18 & 80 & 18 & 45 & 3 & 108 & 440 & 16,38 & 1584,8 \\
\hline & 8 & 51 & 3 & 3 & 40 & 24 & 80 & 24 & 45 & 3 & 96 & 480 & 16,38 & 2631,4 \\
\hline & 10 & 51 & 2 & 3 & 50 & 30 & 80 & 30 & 45 & 3 & 90 & 520 & 16,38 & 3889,2 \\
\hline
\end{tabular}




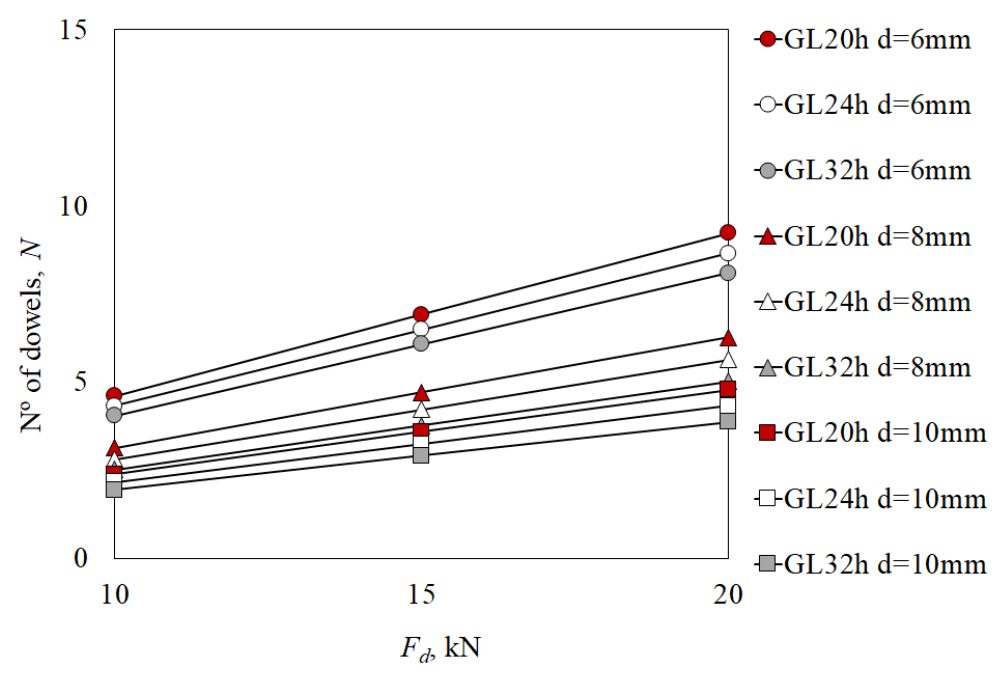

Figure 6. Applied load versus the number of dowels, in W-S-W connections, $t_{1}=45 \mathrm{~mm}$.

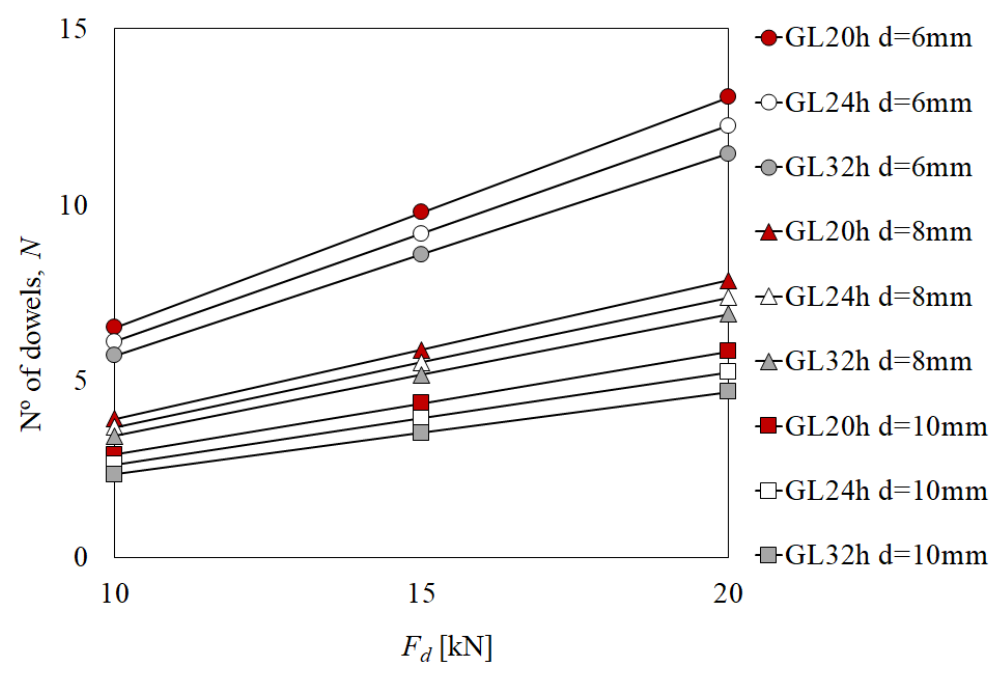

Figure 7. Applied load versus the number of dowels, in $\mathrm{W}-\mathrm{W}-\mathrm{W}$ connections, $t_{1}=t_{2}=45 \mathrm{~mm}$.

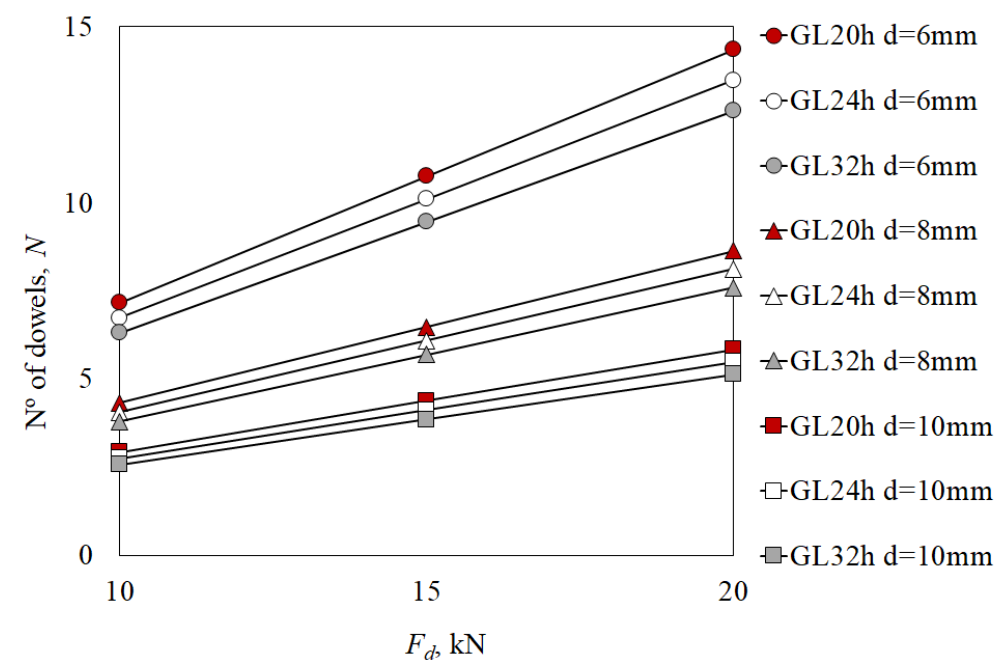

Figure 8. Applied load versus the number of dowels, in S-W-S connections, $t_{2}=45 \mathrm{~mm}$. 


\section{Discussion}

Table 5 presents the failure mode and the correspondent equation that defines the number of dowels, for each wood species and dowel diameter, using different wooden board thickness $t_{1}$ and $t_{2}$. The effect of the two different wooden thicknesses was verified in each connection type. The failure mode associated with each design equation was also identified.

Table 5. The number of steel dowels in W-S-W, W-W-W and S-W-S connections.

\begin{tabular}{|c|c|c|c|c|c|}
\hline \multirow{2}{*}{ Wood } & \multirow{2}{*}{$d, \mathrm{~mm}$} & \multicolumn{4}{|c|}{ W-S-W } \\
\hline & & $t_{1}=45 \mathrm{~mm}$ & Failure mode & $t_{1}=62,5 \mathrm{~mm}$ & Failure mode \\
\hline \multirow{3}{*}{ GL2OH } & 6 & $N=0.461 \times F_{d}$ & Eq.3c & $N=0.461 \times F_{d}$ & Eq.3c \\
\hline & 8 & $N=0.314 \times F_{d}$ & Eq.3c & $N=0.278 \times F_{d}$ & Eq.3c \\
\hline & 10 & $N=0.239 \times F_{d}$ & Eq.3c & $N=0.188 \times F_{d}$ & Eq.3c \\
\hline \multirow{3}{*}{ GL24H } & 6 & $N=0.433 \times F_{d}$ & Eq.3c & $N=0.433 \times F_{d}$ & Eq.3c \\
\hline & 8 & $N=0.282 \times F_{d}$ & Eq.3c & $N=0.261 \times F_{d}$ & Eq.3c \\
\hline & 10 & $N=0.216 \times F_{d}$ & Eq.3c & $N=0.176 \times F_{d}$ & Eq.3c \\
\hline \multirow{3}{*}{ GL32H } & 6 & $N=0.405 \times F_{d}$ & Eq.3c & $N=0.405 \times F_{d}$ & Eq.3c \\
\hline & 8 & $N=0.251 \times F_{d}$ & Eq.3c & $N=0.244 \times F_{d}$ & Eq.3c \\
\hline & 10 & $N=0.194 \times F_{d}$ & Eq.3c & $N=0.165 \times F_{d}$ & Eq.3c \\
\hline \multirow{2}{*}{ Wood } & \multirow{2}{*}{$d, \mathrm{~mm}$} & \multicolumn{4}{|c|}{$\mathbf{W}-\mathbf{W}-\mathbf{W}$} \\
\hline & & $t_{1}=t_{2}=45 \mathrm{~mm}$ & Failure mode & $t_{1}=t_{2}=62,5 \mathrm{~mm}$ & Failure mode \\
\hline \multirow{3}{*}{ GL20H } & 6 & $N=0.653 \times F_{d}$ & Eq. $4 \mathrm{~d}$ & $N=0.653 \times F_{d}$ & Eq. $4 \mathrm{~d}$ \\
\hline & 8 & $N=0.393 \times F_{d}$ & Eq.4d & $N=0.393 \times F_{d}$ & Eq.4d \\
\hline & 10 & $N=0.292 \times F_{d}$ & Eq.4d & $N=0.266 \times F_{d}$ & Eq.4d \\
\hline \multirow{3}{*}{ GL24H } & 6 & $N=0.613 \times F_{d}$ & Eq.4d & $N=0.613 \times F_{d}$ & Eq.4d \\
\hline & 8 & $N=0.369 \times F_{d}$ & Eq.4d & $N=0.369 \times F_{d}$ & Eq.4d \\
\hline & 10 & $N=0.263 \times F_{d}$ & Eq.4d & $N=0.250 \times F_{d}$ & Eq.4d \\
\hline \multirow{3}{*}{ GL32H } & 6 & $N=0.573 \times F_{d}$ & Eq.4d & $N=0.573 \times F_{d}$ & Eq.4d \\
\hline & 8 & $N=0.345 \times F_{d}$ & Eq.4d & $N=0.345 \times F_{d}$ & Eq.4d \\
\hline & 10 & $N=0.235 \times F_{d}$ & Eq.4d & $N=0.234 \times F_{d}$ & Eq.4d \\
\hline \multirow{2}{*}{ Wood } & \multirow{2}{*}{$d, \mathrm{~mm}$} & \multicolumn{4}{|c|}{ S-W-S } \\
\hline & & $t_{2}=45 \mathrm{~mm}$ & Failure mode & $t_{2}=62,5 \mathrm{~mm}$ & Failure mode \\
\hline \multirow{3}{*}{ GL2OH } & 6 & $N=0.718 \times F_{d}$ & Eq. $6 \mathrm{~b}$ & $N=0.718 \times F_{d}$ & Eq.6b \\
\hline & 8 & $N=0.432 \times F_{d}$ & Eq.6b & $N=0432 \times F_{d}$ & Eq.6b \\
\hline & 10 & $N=0.293 \times F_{d}$ & Eq.6b & $N=0.3293 \times F_{d}$ & Eq.6b \\
\hline \multirow{3}{*}{ GL24H } & 6 & $N=0.675 \times F_{d}$ & Eq.6b & $N=0,675 \times F_{d}$ & Eq.6b \\
\hline & 8 & $N=0.406 \times F_{d}$ & Eq.6b & $N=0.406 \times F_{d}$ & Eq.6b \\
\hline & 10 & $N=0.275 \times F_{d}$ & Eq.6b & $N=0.275 \times F_{d}$ & Eq.6b \\
\hline \multirow{3}{*}{ GL32H } & 6 & $N=0.631 \times F_{d}$ & Eq.6b & $N=0.631 \times F_{d}$ & Eq.6b \\
\hline & 8 & $N=0.380 \times F_{d}$ & Eq.6b & $N=0.380 \times F_{d}$ & Eq.6b \\
\hline & 10 & $N=0.257 \times F_{d}$ & Eq.6b & $N=0.257 \times F_{d}$ & Eq.6b \\
\hline
\end{tabular}

For thicknesses of wood elements equal to or greater than $45 \mathrm{~mm}$, some conclusions can be drawn from this study.

In all connection types, the number of dowels increases with the applied tensile load. Also, lower dowel diameter has a more pronounced effect in the number of fasteners. And it is still noticeable the increased number of dowels for lower wood strength and density. In all connections there is a considerable increase in the shear strength for higher dowel diameters, wood density and its strength.

In W-S-W connections, the number of dowels depends on the thickness of the wooden elements, which is not the case for the other connection types. This fact is 
evidenced by the failure mode determined with the minimum value of the characteristic load-carrying capacity per shear plane and fastener given by the Equations in (3), which varies according to the dowel diameter, wood strength and density.

For higher diameters, GL24H and GL32H wood species, the failure mode represents the bending in the connector, in the case of connections with $45 \mathrm{~mm}$ thick elements. By increasing the thickness of the wooden elements, the failure mode results in the combination of effects, the embedment of the wood and bending of the fastener. For smaller dowel diameter and GL20H, the failure mode results in a combination of failure mode in wood embedment and fastener bending. This result is independent of the change in the thickness of the wood elements.

In $\mathrm{W}-\mathrm{W}-\mathrm{W}$ connections, the calculation of the number of dowels is not dependent on the thickness of the wooden elements, when considering thicknesses equal or greater than $45 \mathrm{~mm}$. This fact is supported by the same failure mode, identified from the the minimum characteristic load-carrying capacity per shear plane and fastener. This failure mode represents simultaneous plastic hinge formation in the fastener inside all members and bearing failure of all members.

In S-W-S connections, the number of dowels is independent of the thickness of the wooden elements and presents the same failure mode, for thicknesses equal to or greater than $45 \mathrm{~mm}$. This failure mode represents the embedment of the wood, and bending of the fastener and failure, both in conjunction.

The results show that S-W-S connection needs a higher number of dowels when compared with the other connections type, especially the connection GL20H with a dowel diameter equal to $6 \mathrm{~mm}$. On the other hand, the W-S-W connections need the lower number of dowels according to the design equations, namely GL32H connection needs the lower number of dowels when using a diameter equal to $10 \mathrm{~mm}$.

\section{Conclusions}

The methodologies to assess the safe design, for three wood connections type in double shear, which is proposed by Eurocode 5, part 1-1 [8], are presented and the influence of the design parameters are analyzed by studying. a large number on bolted connections. The connection design is dependent on the failure mode, being this defined for each wood connection types. The results are extremely useful to obtain the typical dimensions needed for any connection type and to verify the influence of the wood strength and density.

The following general conclusions can be drawn:

- The number of dowels increases with the tensile load.

- Lower dowel diameters have a higher influence in the number of fasteners.

- The number of dowels increases with lower wood density properties.

- The number of dowels increases with lower wood strength properties.

- The influence of the wood elements thicknesses on the number of dowels is negligible for values equal or greater than $45 \mathrm{~mm}$.

Based on the presented work, a need for further research can be defined related to the study of different connection configurations and fasteners in use. Also, it is intended to compare the effect of wood strength and density in connections in single shear.

Author Contributions: Conceptualization, E.M.M.F; methodology, H.M.L.; validation, P.A.S.L., L.D.S.S., V.S.B.S.; investigation, P.A.S.L., L.D.S.S., V.S.B.S.; writing-original draft preparation, E.M.M.F.; writing - review and editing, E.M.M.F., H.M.L.; supervision, E.M.M.F. All authors have read and agreed to the published version of the manuscript.

Funding: This research received no external funding.

Conflicts of Interest: The authors declare no conflict of interest.

\section{References}

1. Peng, L. Performance of heavy timber connections in fire. Dissertation, Carleton University, Canada, 2010. 
2. Amorim, F.; João, N. Projecto de Estruturas de Madeira. Publindústria (ed), Portugal, 2008.

3. Chuang Miao, D.F., Michael T. Heitzmann, Henri Bailleres, GFRP-to-timber bonded joints: Adhesive selection. International Journal of Adhesion and Adhesives 2019, 94, 29-39.

4. Laboratory, F.P. Wood Handbook - Wood as an Engineering Material. General Technical Report FPL-GTR-190, Centennial Edition, Madison, Wisconsin - U.S. Forest Service, 2010, 508p.

5. Peng, L.; Hadjisophocleous, G.; Mehaffey, J.; Mohammad, M. On the Fire Performance of Double-shear Timber Connections. Fire Safety Science 2011, 10, 1207-1218. doi:10.3801/IAFSS.FSS.10-1207

6. Frangi, A.; Erchinger, C.; Fontana, M. Experimental fire analysis of steel-to-timber connections using dowels and nails. Fire and Materials 2009, 34(1), 1-19. doi:10.1002/fam.994

7. Fonseca, E.M.M.; Leite, P.A.S.; Silva, L. Wood Connections Under Fire Conditions Protected with Gypsum Plasterboard Types A and F. Chapter No:7, In Book Advances in Fire Safety Engineering. CILASCI 2019. P.A.G. Piloto et al (Eds), Lecture Notes in Civil Engineering, Cham, Springer Nature Switzerland, 2020, Volume 1, pp. 93-106. doi:10.1007/978-3-030-36240-9_7

8. European Committee for Standardization, Eurocode 5: Design of timber structures. Part 1-1: General Common rules and rules for buildings. Brussels, BSI, 2004.

9. Porteous, J.; Kermani, A. Structural Timber Design to Eurocode 5. Blackwell Publishing, 2007.

10. Laboratory, F.P. Wood Handbook - Wood as an Engineering Material. General Technical Report FPL-GTR-190, Centennial Edition ed., Madison, Wisconsin U.S. Department of Agriculture, Forest Service, Forest Products Laboratory, 2010, 508p.

11. Green, D.W.; Winandy, J.E.; Kretschmann, D.E. Mechanical Properties of Wood. Chapter 4 In Book Wood Handbook, Madison, Department of Agriculture, Forest Service, Forest Products Laboratory, 1999, 463p.

12. British Standards Institution. Timber structures. Glued laminated timber. Strength classes and determination of characteristic values. London: BSI, 1999.

13. Hasslacher Norica Timber. Glued Laminated Timber. The Engineering Timber Beam, Germany. Available online: https://www.hess-timber.com/en/products/glued-laminated-timber/ . (Accessed 29 September 2021).

14. Jozef Gocál, Load Carrying Capacity of Metal Dowel Type Connections of Timber Structures, Civil and Environmental Engineering 2014, 10(2), 51-60. doi:10.2478/cee-2014-0011

15. Martins, D.A.R.; Fonseca, E.M.M. Fire Behaviour of Protected W-S-W Connections with a Steel Plate as the Central Member and Different Dowels Diameter. International Journal of Science and Technology 2018, 4(3), 60-78. doi.10.20319/mijst.2018.43.6078

16. Fonseca, E.M.M.; Silva, L.; Leite, A.S.P. Fire safety of wood-steel connections. In 4th International Conference on Numerical and Symbolic Computation Developments and Applications - Developments and Applications, Maria Amélia, Joaquim Barbosa et al. (eds), Porto, 2019, 109-118.

17. Silva, V.; Fonseca, E.M.M. Design of steel-wood-steel connections at the ambient and elevated temperatures. Journal of Computational Applied Mechanics 2021, 52(1), 85-101. doi:10.22059/JCAMECH.2021.315728.579

18. Fonseca, E.M.M.; Silva L.; Leite, P.A.S. Numerical model to predict the effect of wood density in wood-steel-wood connections with and without passive protection under fire Journal of Fire Sciences, 2020, 38(2), 122-135. doi:10.1177/0734904119884706

19. European Committee for Standardization, Eurocode 5: Design of timber structures. Part 1-2: General Structural fire design. Brussels, BSI, 2004. 